\title{
Towards Semi Automated Pre-assembly for Aircraft Interior Production
}

\author{
Florian Kalscheuer (10, Henrik Eschen (1) \\ and Thorsten Schüppstuhl (1)
}

\begin{abstract}
The growing aviation market puts first tier suppliers of aircraft interior under great pressure. Cabin monuments, not only consist of various assemblies with a wide range of parts, they are also highly customized by the airliners. Historically grown, poorly optimized manual processes offer the required flexibility, but limit the production rate of the individual products. The aviation industry responds with an increased use of automation technology. Recent standardization and automation approaches for efficient manufacturing, lead to an increase in productivity of these low volume products. However, complementary approaches to increase the degree of automation during assembly of aircraft interior components are missing. To reach a higher degree of automation this paper presents a derivation of cabin specific assembly processes with a varying degree of automation. First the range of components and processes in pre-assembly is analyzed with respect to automation. Based on the analysis, components and processes are classified in standardized groups. Fully automated and flexible automation processes are introduced to develop a semi-automated system. Furthermore, the required flow of information is described. Discussion of the results shows that the presented solution allows a flexible pre-assembly of low-volume interior parts and sets a baseline for further digitalization approaches.
\end{abstract}

\section{Keywords}

Pre-assembly $\cdot$ Aircraft interior $\cdot$ Hybrid assembly $\cdot$ Digitalization

F. Kalscheuer $(\bowtie) \cdot$ H. Eschen · T. Schüppstuhl

Institute for Aircraft Production Technology, Hamburg University of Technology,

Denickestraße 17, 21073 Hamburg, Germany

e-mail: florian.kalscheuer@tuhh.de

URL: https://tuhh.de/ifpt

T. Schüppstuhl et al. (eds.), Annals of Scientific Society for Assembly,

Handling and Industrial Robotics 2021,

https://doi.org/10.1007/978-3-030-74032-0_17 


\section{Introduction}

\subsection{Motivation and Problem Statement}

The aviation market is constantly growing. Until recently, the two biggest OEMs Boeing and Airbus both predicted a demand of new airliners which would increase the existing global fleet to 50,000 aircraft by 2038 [1, 4]. Despite the COVID-19 crisis and the sudden increase in cancellations of aircraft orders in March 2020 global revenue passenger kilometers are predicted to recover at $10 \%$ below the pre COVID level in 2025 [2, 5, 18]. During the 25-year lifespan of an aircraft [1], the cabin interior is re-furbished in intervals of 5-10 years $[3,25]$. The line fit products, combined with these so called "retrofit monuments" result in an aftermarket "that is typically two to three times bigger than the OEM market" [27].

Although the abovementioned numbers will decrease, first tier suppliers have to remain competitive in an increasingly consolidated market [22]. On the one hand, previous publications primarily address automation approaches for manufacturing processes e.g. robot supported installation of threaded inserts, pressure-controlled potting of honeycomb panels and concepts for the automated manufacturing of flat sandwich panels $[8,9,14$, 19]. These works can be classified as digital aircraft interior production and set a digitalization baseline for downstream processes. On the other hand, suppliers face the assembly of customized, highly individual lightweight panels with a high proportion of manual tasks. These provide to the required flexibility, but cannot be carried out economically in a high wage country. To increase the productivity they either outsource work to low-wage countries or strive for a higher degree of automation. However, the interior assembly does not provide an adequate database and a categorization and parametrization of tasks and data for digital, automated assembly in lot size 1 as well as cabin specific assembly concepts are missing.

Since the automated manufacturing of flat lightweight panels promises a high standardization potential, this paper pursues the approach of the automation of the pre-assembly of flat lightweight panels. The goal is to give a detailed overview of the existing parts and their respective processes, as well as an evaluation and parametrization towards automated assembly in order to set a baseline for digital assembly solutions. At last, a partial demonstrator for a hybrid-assembly station will be described which allows further research in the field of cabin interior assembly.

\subsection{Automation Approaches for Interior Production}

Besides the automated manufacturing approaches mentioned in Sect. 1.1 only a few other publications regarding the automation aircraft interior assembly exist. Halfmann et al. [12] defined a concept for the final assembly line in aircraft factories which allows the manual pre-assembly of e.g. hatracks, passenger service units and lining panels outside the 
fuselage to reduce lead-time and working hours. Other concepts focus on a modular, assembly-friendly design of interior components or the application of augmented reality tools for faster cabin conversions [7, 11, 13]. Fette et al. [10] introduced a concept of robot-supported assembly of an overhead storage compartment. The abovementioned publications address the assembly either of complete monuments at the OEMs production line during line fit or the assembly of monuments from single panels and do not contribute to an increased productivity during the assembly of the subassemblies themselves.

Currently, composite sandwich structures made of a honeycomb core and pre-impregnated glass-fiber facesheets show large tolerances and are not optimized for automated assembly processes. The optimized panel design in combination with an automated potting process which was introduced in Eschen et al. [8] allows to produce individual panels with functional properties like solid wooden panels used in the furniture industry. Machine and plant manufacturers such as HOMAG Group offer specific solutions for the furniture industry to produce pieces of furniture in small batch sizes or even batch size one. Together with digital solutions such as manufacturing executions systems (MES) and the connected drilling, milling, sawing and edge banding machines, they provide highly automated production systems [16]. Specific configurations for customized lightweight panels are not addressed. Furthermore, chained, fully automated assembly systems do not meet the custom framework of cabin interior production. Standardized and assembly-oriented design of parts and subassemblies as well as a digital database are missing.

Huang et al. [17] present a skill-based programming system for automated assembly of furniture sets with robots using a library of skills and artificial intelligence. Knepper et al. [20] implement a furniture assembly system which consists of two KUKA youBots to assemble an IKEA Lack table with a planning algorithm which requires only the geometric form of the components as an input. The described concepts are not transferable economically, since the programming effort still exceeds economically justifiable process improvement and the necessary process standardization is missing.

Current research shows, that these limitations can be overcome by a combination of automated systems and worker supporting systems, creating an economically functioning, semi-automated assembly system. Müller et al. [23] introduced a modular production equipment for visual assistance which can implement different projection devices using MQTT and Node-RED for the application in different industries. Müller et al. [24] presents an approach for cognitive assistance to handle deviations from repetitive process flows in assembly. Furthermore, commercial solutions such as "Der Schlaue Klaus" (Optimum) offer visual assistance for assembly and quality assurance using image processing. However, such systems have not been integrated in aircraft interior assembly and the specific requirements for these systems have not been analyzed yet. 


\subsection{Outline}

In order to give an overview of involved components and processes and to identify solutions to reach a higher degree of automation, first the current range of components and the existing assembly processes are analyzed. These results can further be evaluated with respect to automatability and classified into different categories. This allows to develop cabin specific assembly processes with a varying degree of automation. Since existing, manual production systems for highly individual components do not provide a data basis for the integration of automated systems, the flow of information will be analyzed and discussed. This includes the identification of process specific parameters, as data input for the control of automated or semi-automated systems. Since semi-automated (hybrid) systems require a consideration of human tasks, a partial demonstrator of a hybrid assembly station is introduced and described before the results are discussed.

\section{Pre-assembly of Aircraft Interior}

\subsection{Range of Components in Pre-assembly}

The production process used for the production of aircraft interior monuments can be divided in the manufacturing and machining of raw panels, the pre-assembly of sub-assemblies and the final assembly of complete monuments. All processes that use a single sandwich panel as a base part are allocated in the pre-assembly e.g. mounting of threaded inserts and dowels by gluing or fastening attachment parts with screws. Joining different panels to create a complete monument as well as the application of e.g. electrical wires, air and water pipes are considered as a part of the final assembly. All processes are currently executed manually.

The pre-assembly of interior panels contains a wide range of aircraft interior specific components. Assemblies usually consist of threaded inserts, edge protection, lock fittings, guiding rails, retainers and intermediate retainers, bumper plates, hinges and lamp housings. The base component which is considered in the following analysis, is a flat honeycomb panel manufactured as described in 1.1. This basic structure is shown in Fig. 1 using the example of a service-unit panel. Three different types of inserts, attachment parts with individual geometries and parts are assembled onto surfaces in all joining directions.

Besides the variation of different attachment parts, the threaded inserts form the numerically largest group of components in pre-assembly. They are used to create joints for screws and can be subdivided in three different categories: cylindrical inserts (potted inserts), cylindrical inserts with a one-sided flange and high-load inserts.

Potted inserts are usually made of metal or fiber-reinforced plastic (FRP) and a stainless-steel thread. They are mounted in drilled holes on the top and bottom sur-face or front surfaces for the attachment of low-, medium- and high-loaded components. In some 


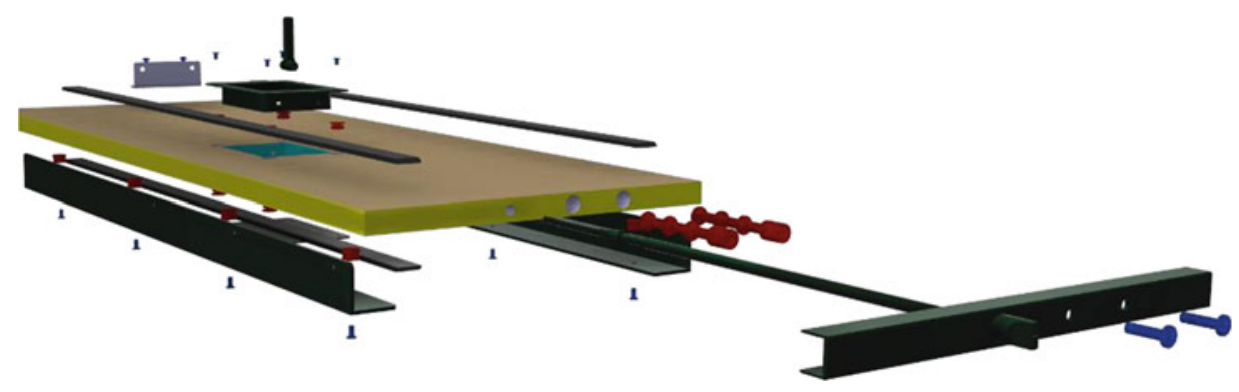

Fig. 1 Basic structure of a service-unit panel

cases, potted inserts can be substituted by so called friction-inserts. They have a thermoplastic coating, that is melting while drilling them into the honey-comb panel to create a form-fit connection [15]. The cylindrical inserts with a one-sided flange and the high-load inserts are made of aluminum and a stainless-steel thread. The flange is used to transfer loads into the face sheets. The core diameter of the high loaded inserts is similar to the cylindrical inserts. However, its length is about four times higher and it has three shaft shoulders along its length. Furthermore, other special types of inserts exist. Between insert and part assembly, a decorative film is applied.

\subsection{Range of Pre-assembly Tasks}

The pre-assembly tasks are divided in five different operations joining, handling, inspection, adjustment and additional tasks according to Lotter and Wiendahl [21]. Predominantly, primary assembly tasks such as joining and handling can be found and are listed in Fig. 2.

\begin{tabular}{|c|c|c|c|}
\hline \multirow{5}{*}{$\begin{array}{l}\text { Assembly } \\
\text { tasks }\end{array}$} & Joining & $\begin{array}{ll}\text { - } & \text { Adhesive } \\
\text { application } \\
\text { - } & \text { Adhesive bonding }\end{array}$ & $\begin{array}{ll}\text { - } & \text { Screwing } \\
\text { - } & \text { Composing } \\
\text { - } & \text { Friction } \\
& \text { welding }\end{array}$ \\
\hline & Handling & $\begin{array}{ll}\text { - } & \text { Pick-and-place } \\
\text { - Orientating }\end{array}$ & - Placement \\
\hline & Inspection & - Torque Control & $\begin{array}{l}\text { Presence } \\
\text { monitoring }\end{array}$ \\
\hline & Adjustment & \multicolumn{2}{|c|}{ - } \\
\hline & Additional tasks & \multicolumn{2}{|l|}{ - Highlighting } \\
\hline
\end{tabular}

Fig. 2 Assembly tasks during aircraft interior pre-assembly 
The assembly sequence can be described as follows. First, all inserts are mounted into the panel. Either friction welding or two-component adhesive is used to create a form-fit connection. The remaining parts are joined mostly with screws. A few parts are joined by adhesive bonding. Usually, each part is attached separately to the panel. Only a small amount of parts requires simultaneous handling of more than one component.

Since airlines and OEMs use the cabin as a unique selling point over competitors, most of the time cabin interior is custom made and produced in small lot-sizes. Also, the parts themselves undergo changes in geometry and material. In addition, the number of parts of an assembly as well as joining positions vary.

\section{Semi-Automated Assembly of Aircraft Interior}

\subsection{Automation-Oriented Classification of Parts and Their Corresponding Assembly Processes}

For an increased degree of automation during the pre-assembly of aircraft interior, solutions have to be found for a high amount of different parts and individual assembly processes. Therefore, the parts and processes are analyzed with respect to automation-oriented product design based on the guidelines mentioned in Boothroyd et al. [6], Lotter and Wiendahl [21], Ponn and Lindemann [26], Stelzer et al. [28]. The design criteria allow to classify groups of parts (GP) with similar, automation-friendly assembly processes within the pre-assembly (Fig. 3). Because of high safety restrictions in product approval in the aviation industry and since cabin products must be able to be reproduced unchanged over a long period of time, assembly-oriented design changes cannot be considered. The honeycomb panel itself can be considered as an assembly friendly base part. The large support surface ensures stable positioning and no assembly path is geometrically blocked. The front faces are easily accessible.

The first group of parts (GP1) consists of various types of inserts. All can be joined unidirectional in a linear motion and their position is defined by drilled blind holes. GP2 consists of attachment parts that can be described as 2-dimensional or 2, 5-dimensional. They maintain the flat support surface of the base part after they are assembled so the assembly remains automation-friendly. They can be joined unidirectional by adhesive or screws. However, their position on the base part and their orientation is not defined by any geometric feature.

GP3 consists of parts that can be described as 3-dimensional. The parts are joined unidirectional and their position is usually defined by the corresponding inserts. Joining position as well as the screws can easily be accessed. Whereas all these parts can be joined vertically, unidirectional, collision free, are easy to handle and joined separately, some special parts are remaining (GP4). They cannot be considered automation-friendly since they require simultaneous handling of multiple parts, have multidirectional joining paths and have difficult to grasp contact surfaces. 


\begin{tabular}{|c|c|c|c|}
\hline Parts & Process & \multicolumn{2}{|c|}{ Parameter } \\
\hline \multirow[b]{2}{*}{ GP1 } & $\begin{array}{l}\text { Insert handling } \\
\qquad+ \\
\text { friction welding }\end{array}$ & $\begin{array}{ll}\text { - } & \text { Initial position } \\
\text { - } & \text { Final position } \\
\text { - } & \text { Diameter }\end{array}$ & $\begin{array}{l}\text { - Rotational speed } \\
\text { - Process time }\end{array}$ \\
\hline & $\begin{array}{c}\text { Insert handling } \\
+ \\
\text { adhesive } \\
\text { application }\end{array}$ & $\begin{array}{ll}\text { - } & \text { Initial position } \\
\text { - } & \text { Final position } \\
\text { - } & \text { Orientation }\end{array}$ & $\begin{array}{l}\text { - Insert diameter } \\
\text { - Adhesive volume }\end{array}$ \\
\hline GP2 & $\begin{array}{l}\text { Part handling }+ \\
\text { (highlighting) }+ \\
\text { adhesive/force } \\
\text { application }\end{array}$ & $\begin{array}{ll}\text { - } & \text { Initial position } \\
\text { - } & \text { Final position } \\
\text { - } & \text { Orientation } \\
\text { - } & \text { Joining face contour }\end{array}$ & $\begin{array}{ll}\text { - } & \text { Part weight } \\
\text { - } & \text { Part dimension } \\
\text { - } & \text { Adhesive volume }\end{array}$ \\
\hline GP3 & $\begin{array}{c}\text { Part handling }+ \\
\text { (highlighting) } \\
+ \\
\text { screwing }\end{array}$ & $\begin{array}{ll}\text { - } & \text { Initial position } \\
\text { - } & \text { Final position } \\
\text { - } & \text { Joining face contour } \\
\text { - } & \text { Part weight }\end{array}$ & $\begin{array}{l}\text { - } \text { Part dimension } \\
\text { - } \text { Type of screw } \\
\text { - } \\
\text { - } \text { Trill hole position } \\
\text { Process time }\end{array}$ \\
\hline GP4 & $\begin{array}{l}\text { Handling of } \\
\text { multiple parts } \\
\quad+ \\
\text { joining task }\end{array}$ & $\begin{array}{l}\text { - Initial position } \\
\text { - } \text { Final position } \\
\text { - Orientation } \\
\text { - } \text { Assembly sequence } \\
\text { Joining face contour }\end{array}$ & 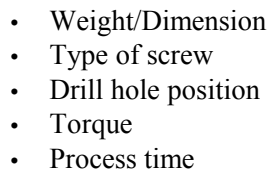 \\
\hline
\end{tabular}

Fig. 3 Groups of parts, respective processes and process parameters

\subsection{Parametrized Assembly Processes}

Although most of the parts and their assembly operations can be considered as easy to automate, the effort in production planning increases as soon as automation technology is implemented, particularly when integrated in manual assembly systems. To contribute to a digital description of the processes along the digital production process chain the identified groups of parts are analyzed with regard to their required input parameters (Fig. 3).

Due to comparably simple base parts and predominantly one-dimensional joining directions, processes can be found which vary only in a small number of specific input parameters. The insert placement process only varies in its final position whereas for highlighting and handling, the dimensions and joining faces are required to define gripping position and highlighted contours. The remaining parameters are defined once for each component and are not process-specific.

\subsection{Research Demonstrator for Hybrid-Assembly}

The classification of components and the description of their respective assembly operations yield potential for automation. Numerically predominant and easy to automate, 

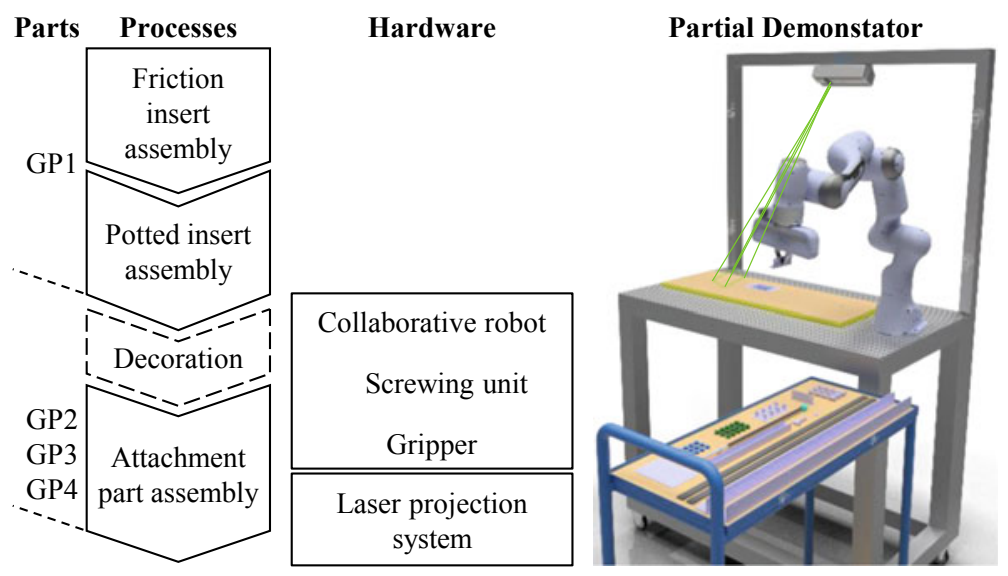

Fig. 4 Research demonstrator for hybrid interior assembly

insert assembly can be fully automated. Numerically low represented attachment parts with different geometries require manual work, which can be supported by assistance systems.

In an ongoing research project, a semi-automated assembly process has been developed. The process chain and a part of the assembly system is shown in Fig. 4. The demonstrator represents the attachment part assembly. Joining and handling is supported by a collaborative robot and allows parallelization of tasks. The orientation of parts or the assembly sequence can be supported by a laser projection system.

\section{Discussion}

The introduced hardware in combination with the abovementioned processes offer a solution to increase the degree of automation of the current processes. The classification and identification of different groups of parts, with respect to their automation capability contributes to process standardization. High-volume processes such as insert placement and gluing can be fully automated with complete flexibility regarding type, number and position of inserts. Commonly used hardware e.g. gantry kinematics, screwing and adhesive dosing units or grippers can be used for this purpose. However, because of the varying geometry of attachment parts, manual assembly cannot be neglected completely. For assembly tasks which require simultaneous handling of multiple parts in different joining directions, manual assembly is preferred. Nevertheless, the laser projection system or collaborative robot offer flexible worker assistance for material handling, joining or highlighting. This introduced combination of fully automated and semi-automated processes contributes to an increase in productivity during the pre-assembly of aircraft interior components and defines a baseline for future research in the field of cabin interior production. 
The analysis of the required process information for the automated assembly and assistance systems is a first step to a digital process description. These information complements the previously developed digital manufacturing process chain. Part and assembly specific parameters can be derived from existing construction data or are defined once during production planning. Process specific parameters can be easily adapted and executed by the proposed hardware. This contributes to a paperless documentation, distribution of information on the shopfloor and allows quick process reconfiguration for new assemblies. However, production management systems and databases have to be implemented to ensure reliability.

The hybrid approach on pre-assembly shows potential for high process flexibility although manual labor is reduced, due to expandable hardware, such as additional assistance systems like industrial cameras, sensors or a moving head spot.

\section{Summary and Future Work}

In this work, a semi-automated pre-assembly system has been introduced to increase the degree of automation and productivity to enable suppliers to remain competitive with low wage countries. The range of components and assembly processes have been analyzed and classified with respect to their automation capability. Standardized groups of processes have been identified and hardware has been proposed. For further research, a partial demonstrator of a hybrid-assembly station was presented.

In future work, the fully automated solutions for insert placement have to be implemented and the automation of adhesive application has to be investigated. Furthermore, a holistic concept for continuous digital cabin production must be developed which allows to implement further automation solutions in a manual production environment. This requires research regarding efficient assembly planning methodologies for semi-automated assembly systems focusing on flow of information, digitalization and development of data-oriented design criteria to reduce commissioning effort of flexible automation technology. In future work, sensors can be integrated in the hybrid-assembly station to allow e.g. presence or assembly progress monitoring, action recognition or quality ensuring inspection tasks.

Acknowledgements The work presented in this paper is carried out in a project funded by the Federal Ministry of Economic Affairs and Energy of German (BMWi). 


\section{References}

1. Airbus S.A.S.: Global Market Forecast 2019-2038: Cities, Airports \& Aircraft (2020a). https:// www.airbus.com/content/dam/corporate-topics/strategy/global-market-forecast/GMF-2019-2038Airbus-Commercial-Aircraft-book.pdf. Accessed 25 Aug 2020

2. Airbus: Orders and Deliveries (2020b). https://www.airbus.com/aircraft/market/orders-deliveries. html. Accessed 25 Aug 2020

3. Black, S.: Advanced Materials for Aircraft Interiors (2020). https://www.compositesworld. com/articles/advanced-materials-for-aircraft-interiors. Accessed 31 Aug 2020

4. Boeing: Boeing: Commercial Market Outlook (2020a). https://www.boeing.com/commercial/ market/commercial-market-outlook/. Accessed 25 Aug 2020

5. Boeing: Boeing: The Boeing Company: General Information (2020b). https://www.boeing. com/company/general-info/index.page\#/overview. Accessed 25 Aug 2020

6. Boothroyd, G., Dewhurst, P., Knight, W.A.: Product design for manufacture and assembly. CRC Press, Boca Raton, London (2011)

7. Deneke, C., Oltmann, J., Schüppstuhl, T., Krause, D.: Technology Innovations for Faster Aircraft Cabin Conversion. In: AST 2019 (2019)

8. EJOT Holding GmbH \& Co. KG. EJOT-TSSD (2020). https://www.ejot.de/medias/sys_ master/Industry_Flyer/Industry_Flyer/h76/h1e/9047841079326/EJOT-TSSD-Flyer-de-02.18. pdf. Accessed 7 Sep 2020

9. Eschen, H., Harnisch, M., Schüppstuhl, T.: Flexible and automated production of sandwich panels for aircraft interior. Proc. Manuf. 18, 35-42 (2018). https://doi.org/10.1016/j.promfg. 2018.11.005

10. Eschen, H., Kalscheuer, F., Schüppstuhl, T.: Optimized Process Chain for Flexible and Automated Aircraft Interior Production. Proc. Manuf. (2020)

11. Fette, M., Büttemeyer, H., Krause, D., Fick, G.: Development of multi-material overhead stowage systems for commercial aircrafts by using new design and production methods. In: SAE Technical Paper Series (2019)

12.. Halfmann, N., Krause, D.: Towards Innovative Assembly Concepts: Integral Product—and Assembly Structure (2010)

13. Halfmann, N., Krause, D., Umlauft, S.: Assembly Concepts for Aircraft Cabin Installation. In: ASME 2010 10th Biennial Conference, pp. 733-739 (2010)

14. Halfmann, N., Elstner, S., Krause, D.: Product and Process Evaluation in the Context of Modularization for Assembly (2011)

15. Harnisch, M., Schüppstuhl, T.: High Quality Automated Honeycomb Potting with Active Pressure Control (2019)

16. HOMAG Group: Die HOMAG Group auf dem Weg zu Industrie 4.0 (2015). https://www. homag.com/fileadmin/systems/brochures/vernetzte-produkton-industrie40-de.pdf. Accessed 10 Jan 2021

17. Huang, P.-C., Hsieh, Y.-H., Mok, A.K.: A skill-based programming system for robotic furniture assembly. In: 2018 IEEE 16th International Conference on Industrial Informatics (INDIN), Porto, July 2018, pp. 355-361

18. IATA: COVID-19: Outlook For Air Travel in the Next 5 Years (2020). https://www.iata. org/en/iata-repository/publications/economic-reports/covid-19-outlook-for-air-travel-in-the-next5-years/. Accessed 25 Aug 2020

19. Kähler, F., Eschen, H., Schüppstuhl, T.: Automated Installation of Inserts in Honeycomb Sandwich Materials. Proc. Manuf. (2020) 
20. Knepper, R.A., Layton, T., Romanishin, J., Rus, D.: IkeaBot: an autonomous multi-robot coordinated furniture assembly system. In: 2013 IEEE International Conference on Robotics and Automation, Karlsruhe, Germany, May 2013, pp. 855-862

21. Lotter, B., Wiendahl, H.-P.: Montage in der Industriellen Produktion. Springer, Berlin (2012)

22. Morrison, M.: AIX: Diehl Aviation Looks at Next Step as Competitors Consolidate (2020). https://www.flightglobal.com/systems-and-interiors/aix-diehl-aviation-looks-at-next-step-ascompetitors-consolidate/132027.article. Accessed 1 Sep 2020

23. Müller, R., Hörauf, L., Vette-Steinkamp, M., Kanso, A., Koch, J.: The assist-by-X system: calibration and application of a modular production equipment for visual assistance. Proc. CIRP 86, 179-184 (2019). https://doi.org/10.1016/j.procir.2020.01.021

24. Müller, R., Hörauf, L., Speicher, C., Bashir, A.: Situational cognitive assistance system in rework area. Proc. Manuf. 38, 884-891 (2019). https://doi.org/10.1016/j.promfg.2020.01.170

25. Niţă, M.F., Scholz, D.: Business opportunities in aircraft cabin conversion and refurbishing. J. Aerosp. Oper . 1(1-2), 129-153 (2011). https://doi.org/10.3233/AOP-2011-0008

26. Ponn, J., Lindemann, U.: Konzeptentwicklung und Gestaltung technischer Produkte. Springer, Berlin (2011)

27. Red, C.: Composites in Aircraft Interiors, 2012-2022 (2020). https://www.compositesworld. com/articles/composites-in-aircraft-interiors-2012-2022. Accessed 31 Aug 2020

28. Stelzer, R., Grote, K.-H., Brökel, K., Rieg, F., Feldhusen, J. (eds.): Entwerfen, entwickeln, erleben: Methoden und Werkzeuge in der Produktenentwicklung. TUDpress, Dresden (2012)

Open Access This chapter is licensed under the terms of the Creative Commons Attribution 4.0 International License (http://creativecommons.org/licenses/by/4.0/), which permits use, sharing, adaptation, distribution and reproduction in any medium or format, as long as you give appropriate credit to the original author(s) and the source, provide a link to the Creative Commons license and indicate if changes were made.

The images or other third party material in this chapter are included in the chapter's Creative Commons license, unless indicated otherwise in a credit line to the material. If material is not included in the chapter's Creative Commons license and your intended use is not permitted by statutory regulation or exceeds the permitted use, you will need to obtain permission directly from the copyright holder. 